\title{
Uji Aktivitas Antioksidan Ekstrak Daun Jambu Biji
}

\author{
Ratna Purwandari' ${ }^{*}$, Sidiq Subagiyo ${ }^{2}$, Teguh Wibowo ${ }^{3}$ \\ 1SMAN 2 Rembang, Indonesia \\ ${ }^{2}$ SMAN 1 Lasem Rembang, Indonesia \\ 3Jurusan Kimia Fakultas Sains dan Teknologi UIN Walisongo Semarang, Indonesia \\ *Email: ratnapur@gmail.com
}

\begin{abstract}
s
Tujuan penelitian ini adalah untuk mengetahui aktivitas antioksidan ekstrak daun jambu biji terhadap Esherichia coli dan Bacillus subtilis. Senyawa antioksidan dalam daun jambu biji diperoleh dengan cara ekstraksi menggunakan metode Soxhletasi dengan pelarut n-heksana dan metanol. Subjek dalam penelitian ini adalah ekstrak daun jambu biji. Sedangkan objek dalam penelitian ini adalah aktivitas antioksidan ekstrak daun jambu biji. Identifikasi senyawa antioksidan menggunakan metode kromatografi paper disc. Dari hasil penelitian ekstraksi daun jambu biji tersebut membuktikan bahwa ekstrak daun jambu biji mempunyai aktivitas antioksidan terhadap Esherichia coli dan Bacillus subtilis. Sehingga daun jambu biji dapat dimanfaatkan untuk mengobati berbagai jenis penyakit.
\end{abstract}

Kata kunci : baggase; lignin; corrosion inhibitor; inhibition efficiency; potentiodynamic polarization

\section{Pendahuluan}

Aktivitas antioksidan merupakan suatu
aktivitas senyawa yang bersifat untuk
menghambat terjadinya pembentukan radikal
bebas di dalam tubuh. Antioksidan substansi yang
diperlukan tubuh untuk menetralisir radikal bebas
dan mencegah kerusakan yang ditimbulkan oleh
radikal bebas terhadap sel normal. Antioksidan
dapat menstabilkan radikal bebas dengan
melengkapi kekurangan elektron yang dimiliki
radikal bebas dan dapat menghambat terjadinya
reaksi berantai dari pembentukan radikal bebas
(Kikuzaki, etal, 2002).
66

Dalam hal ini antioksidan yang digunakan adalah daun jambu biji. Jambu biji (Psidium guajava) adalah salah satu tanaman herba buah jenis perdu, dalam bahasa Inggris disebut Lambo guava (Suradikusumah, 1989). Tanaman ini berasal dari Brazilia Amerika Tengah, menyebar ke Thailand kemudian ke negara Asia lainnya seperti halnya di negara Indonesia. sampai saat ini telah dibudidayakan dan menyebar luas, di daerah-daerah Jawa. Jambu biji mempunyai banyak nama, sering disebut juga jambu klutuk, jambu siki, atau jambu batu. Jambu tersebut kemudian dilakukan persilangan melalui stek atau 
okulasi dengan jenis yang tanaman jambu lain, sehingga akhirnya mendapatkan hasil yang lebih besar dengan keadaan biji yang lebih sedikit bahkan tidak berbiji yang diberi nama jambu Bangkok karena proses terjadinya dari Bangkok.

Khusus daun jambu biji, sejak lama digunakan untuk pengobatan secara tradisional, dan sudah banyak produk herbal dari sediaan jambu biji. Daun jambu biji mengandung flavonoid, tannin $(17,4 \%)$, fenolat $(575,3 \mathrm{mg} / \mathrm{g})$, polifenol, karoten dan minyak atsiri (Vijayakumar, et al, 2015). Adapun salah satu senyawa dari flavonoid yang terkandung dalam daun jambu biji adalah kuersetin, yang memiliki titik lebur $310^{\circ} \mathrm{C}$, sehingga kuersetin tahan terhadap pemanasan (Daud, M., et al, 2011).

Penelitian yang pernah dilakukan berkisar pada khasiatnya sebagai anti diare. Disamping itu, jambu biji mempunyai khasiat sebagai antiinflamasi, antimutagenik, antioksidan, antidiabetes, antihipertensi, penambah trombosit dan analgesic (Chludil, et al, 2008). Berikut beberapa khasiat jambu biji dalam mengobati penyakit diare, kanker, hipertensi, batuk flu, merawat kulit, mencegah sembelit, diabetes, menurunkan berat badan, sariawan perut, demam berdarah. Ekstrak daun jambu biji juga dapat meningkatkan jumlah trombosit dalam darah (Tachakittirungrod, 2007). Trombosit ini jumlahnya akan menurun sangat drastis pada penderita DBD sehingga mudah terjadi pendarahan. Pengujian lebih lanjut juga membuktikan bahwa ekstrak daun jambu biji ini tidak bersifat racun sama sekali (aman untuk dikonsumsi) (Nurmuhaimina, et al. 2009).

Flavonoid adalah suatu keluarga besar berasal dari metabolit sekunder tanaman yang memiliki berbagai fungsi biologis yang menakjubkan dan berbeda. Di antaranya, aktivitas antioksidan. Baru-baru ini telah dilakukan studi yang berfokus pada potensi flavonoid untuk menengahi saraf (Zuhra, 2008). Flavonoid memiliki struktur yang khas, yaitu adanya dua benzena yang terikata oleh rantai propana. Flavonoid dibagi menjadi beerapa jenis berdasarkan bentuk dasarnya, yaitu Flavonoid, isoflavonoid dan neoflavonoid (Indariani, 2010). Selain jenis dan klasifikasi flavonoid, biosintesis flavonoid yang berasal dari dua jalur yaitu poliketida dan fenilpropanoid.

Ekstraksi adalah penyarian zat-zat aktif dari bagian tanaman obat. Adapun tujuan dari ekstraksi yaitu untuk menarik komponen kimia yang terdapat dalam simplisia. Tujuan ekstraksi adalah untuk menarik semua komponen kimia yang terdapat dalam simplisia. Pemisahan secara ekstraksi didasarkan pada perpindahan massa komponen zat padat ke dalam pelarut dimana perpindahan mulai terjadi pada lapisan antar muka, kemudian berdifusi masuk ke dalam pelarut (Prakash, A., 2001).

Metode ekstraksi dapat dibagi menjadi dua jenis, yaitu metode ekstraksi secara dingin dan metode ekstraksi secara panas. Adapun pada metode ekstraksi secara dingin dapat digunakan metode maserasi dan metode soxhletasi (Rohyami, 2008). Soxhletasi merupakan penyarian sampel secara berkesinambungan. Cairan penyari dipanaskan sehingga menguap, uap cairan penyari terkondensasi menjadi molekul-molekul cairan oleh pendingin balik dan turun menyari simplisia dalam klongsong. Cairan penyari selanjutnya masuk kembali ke dalam labu alas bulat setelah melewati pipa sifon.

\section{Metode Penelitian}

\section{Alat dan Bahan}

Peralatan yang digunakan adalah blender, seperangkat soxhlet, neraca analitik, pipet tetes, penggaris, gelas ukur, cawan petri, spreader, incubator, dan Erlenmeyer. 
Bahan yang digunakan adalah daun jambu biji, n-heksana, methanol, kertas saring, kertas sampul, paper disc, dan media agar.

Prosedur Kerja

\section{Ekstraksi Daun Jambu Biji}

$20 \mathrm{~g}$ daun jambu biji kering

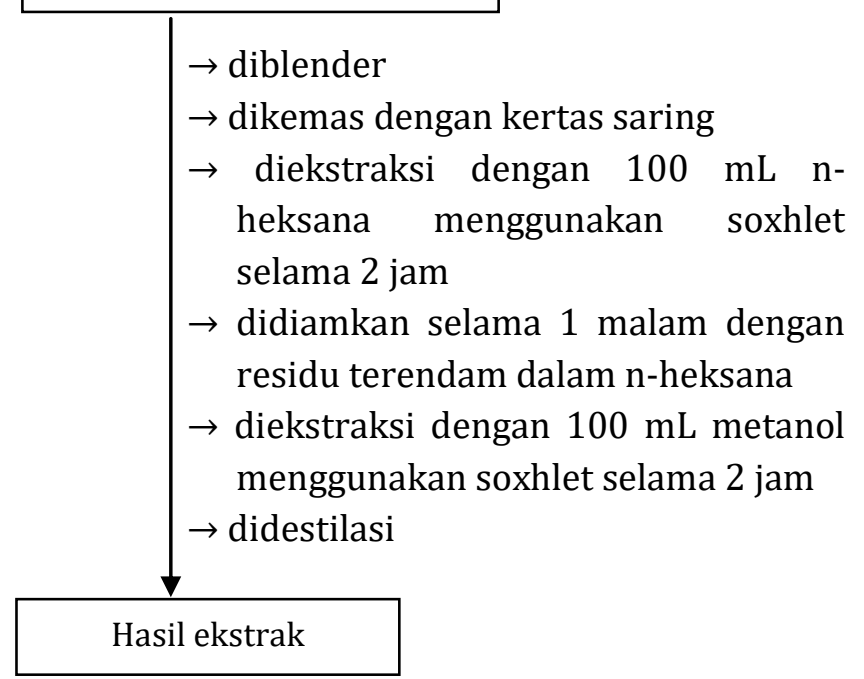

\section{Uji Aktivitas Antioksidan Ekstrak Daun Jambu Biji}

Uji Aktivitas Antioksidan terhadap Esherichia coli

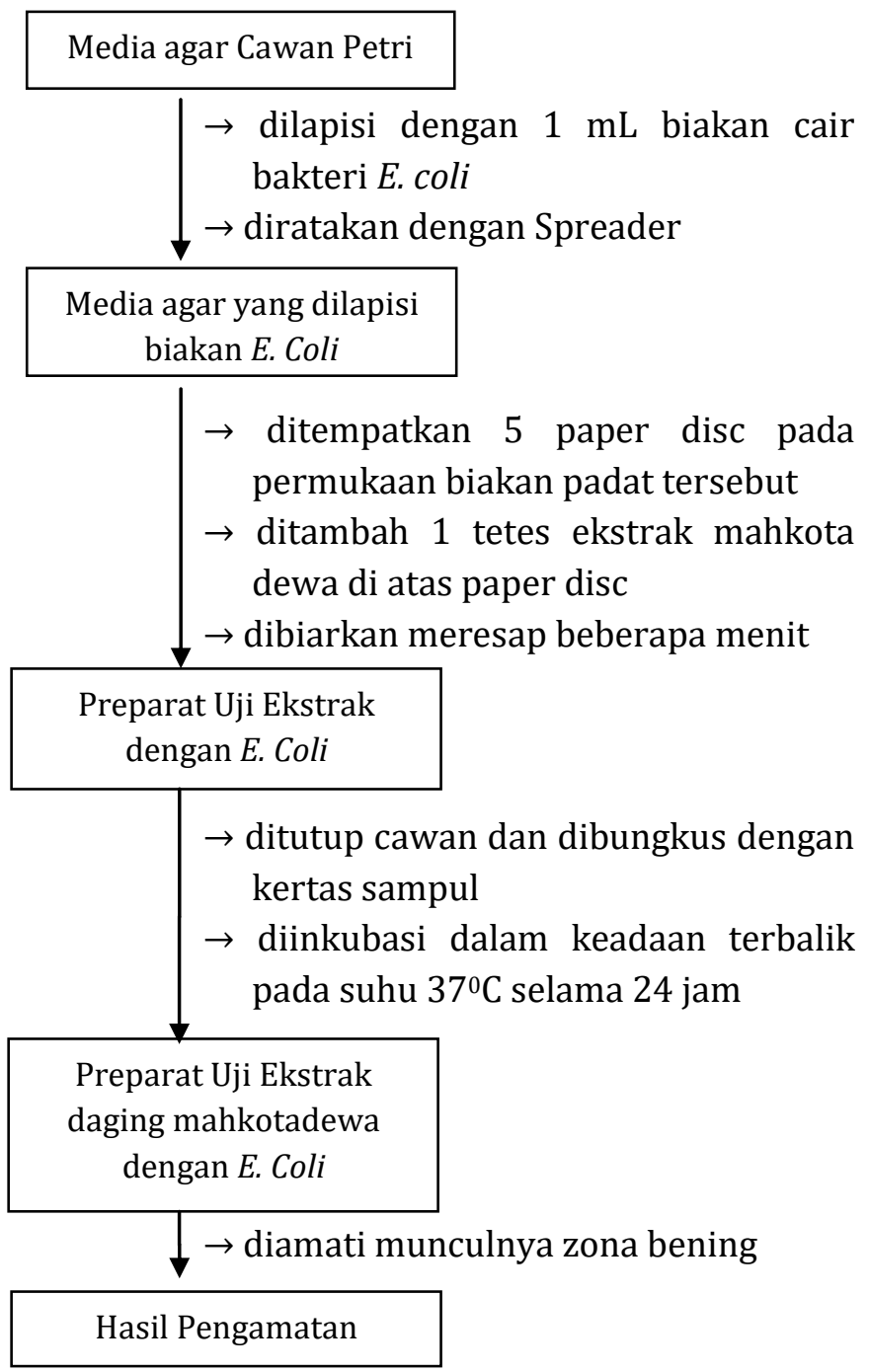


Uji Aktivitas Antioksidan terhadap Bacillus subtilis

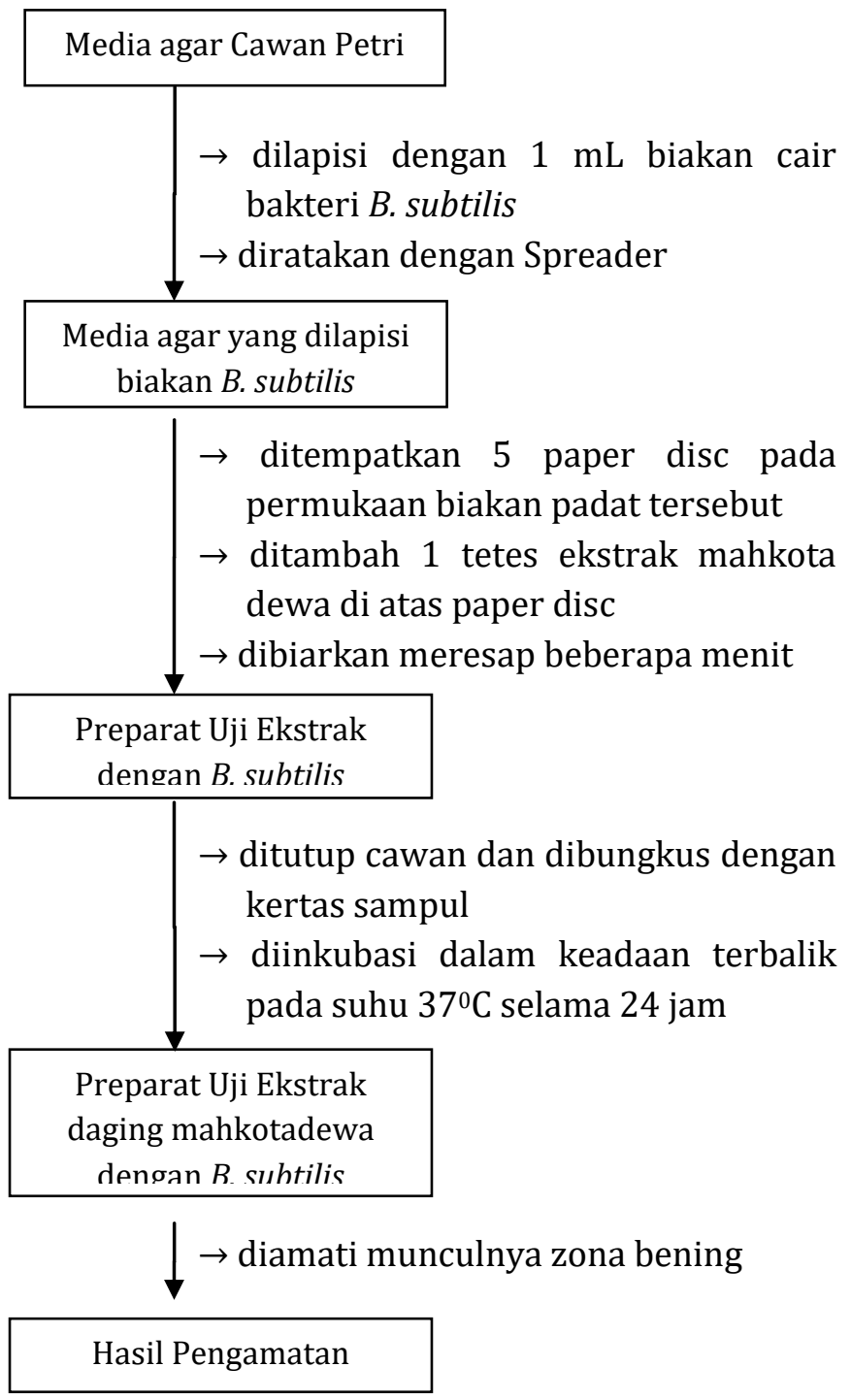

\section{Hasil dan Pembahasan}

\section{Ekstraksi Soxhlet}

Sebelum proses ekstrasi menggunakan soxhlet, daun biji jambu dikeringkan terlebih dahulu dan dihaluskan dengan blender. Hal ini bertujuan untuk mendapatkan ukuran atau luas permukaan bahan yang kecil. Ukuran bahan yang akan diekstrak dapat mempengaruhi efisiensi ekstraksi. Ukuran bahan yang terlalu besar mengakibatkan kontak antara komponen yang akan dipisahkan lebih kecil. Jika ukuran bahan lebih kecil, maka pelarut lebih mudah berinteraksi dengan komponen yang akan dipisahkan.

Ekstraksi dilakukan menggunakan penangas air untuk menjaga agar tidak terjadi kelebihan temperatur selama pemanasan. Ekstraksi dilakukan selama 2 jam, sehingga perlu dihindari terjadinya bumping.

Dengan adanya pemanasan, pelarut akan mencapai titik didihnya. Pada saat pelarut mendidih, terjadi kesetimbangan antara fasa uap dengan fasa cair dalam labu alas bulat. Fasa uap keluar melalui pipa menuju ke pendingin dan akhirnya mengembun. Embun menetes pada soxhlet mengenai serbuk daun jambu biji. Pelarut ditampung dalam soxhlet untuk sementara waktu sampai tingginya mencapai tinggi pipa kapiler.

Selama ditampung di dalam soxhlet terjadi kontak yang lebih lama antara bahan yang diekstrak dengan pelarut sehingga pemisahan lebih optimal. Setelah tingginya sama dengan tinggi pipa kapiler, pelarut yang telah membawa komponen yang akan dipisahkan kembali ke labu alas bulat. Pelarut akan mendidih kembali dan menguap menuju kondensor. Komponen yang dipisahkan tetap berada dalam labu alas bulat. Proses ini berlangsung secara terus-menerus sampai komponen yang akan dipisahkan dapat larut dalam pelarut.

Ekstraksi dilakukan dua langkah, yaitu ekstraksi menggunakan pelarut n-heksana dan ekstraksi menggunakan pelarut metanol. Ekstraksi yang dilakukan dengan menggunakan pelarut nheksana dimaksudkan untuk memisahkan senyawa-senyawa non polar yang terdapat dalam daging buah mahkota dewa. Pelarut ini termasuk pelarut non polar, sehingga dapat melarutkan senyawa-senyawa non polar yang terdapat di dalamnya.

Pelarut n-heksana yang digunakan untuk memisahkan senyawa non polar sebanyak $100 \mathrm{~mL}$. Ekstraksi berlangsung terus-menerus sampai fraksi n-heksana menjadi tidak berwarna. Ekstraksi berlangsung selama 2 jam. Agar pemisahan lebih optimal, ekstrak didiamkan 
selama satu malam. Pemanasan dihentikan ketika soxhlet mendekati penuh, sehingga pada saat didiamkan selama 1 malam residu dalam keadaan terendam n-heksana.

Kemudian residu yang telah terbebas dari senyawa non polar diekstrak dengan $100 \mathrm{~mL}$ metanol. Ekstraksi dilakukan sampai metanol yang berada dalam soxhlet menjadi tidak berwarna. Proses ini berlangsung selama 2 jam. Ekstrak nheksana pada sampel buah yang diperoleh berwarna kuning tua. Ekstrak ini mengandung senyawa-senyawa nonpolar yang terdapat dalam daging buah mahkota dewa, begitu pula pada ekstrak metanolnya, Untuk menghilangkan kemungkinan terganggunya ekstrak oleh pelarut methanol yang digunakan, maka ekstrak didestilasi menggunakan alat destilasi. Destilat inilah yang selanjutnya akan diidentifikasi adanya senyawa flavonoid yang diduga merupakan senyawa yang berperan sebagai antioksidan.

\section{Uji Antioksidan Ekstrak Daun Jambu Biji}

Uji aktivitas antimikrob menggunakan media agar yang diinkubasi selama satu minggu. Pada uji ini diamati diameter zona bening di sekitar paper disc terhadap Esherichia coli dan Bacillus subtilis, yang menunjukkan bahwa ekstrak daging mahkota dewa mempunyai aktivitas antioksidan.

Hasil pengamatan zona bening setelah masa inkubasi selama satu minggu seperti pada gambar berikut:

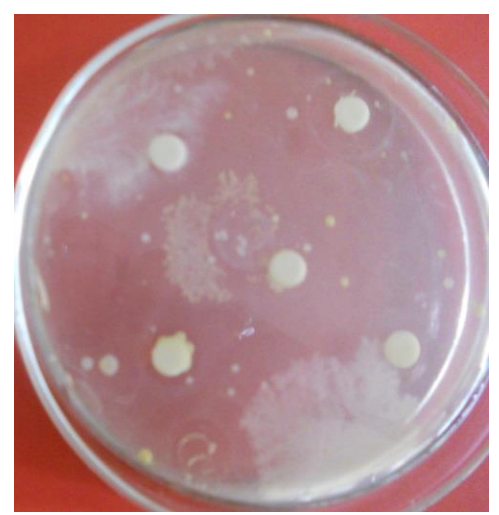

Gambar 1. Uji Ekstrak Pada Esherichia coli

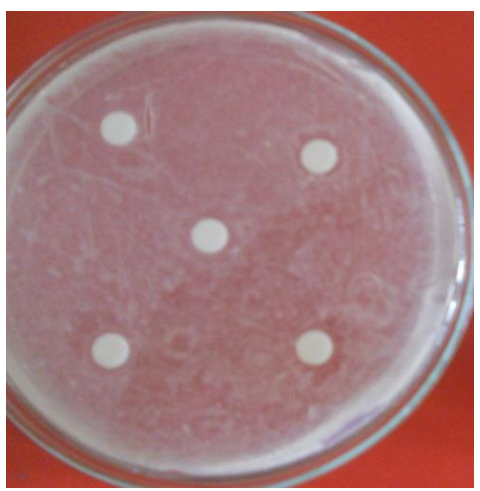

Gambar 2. Uji Ekstrak Pada Bacillus subtilis

Berdasarkan gambar dapat dilihat bahwa pada Esherichia coli dan Bacillus subtilis terdapat zona bening. Hal ini berarti bahwa ekstrak daun jambu biji mempunyai aktivitas antioksidan terhadap Esherichia coli dan Bacillus subtilis. Selain itu, terlihat juga bahwa zona bening pada Esherichia coli jauh lebih luas dibandingkan dengan zona bening pada Bacillus subtilis. Hal ini berarti bahwa aktivitas antioksidan ekstrak daun jambu biji terhadap Esherichia coli lebih besar dari pada terhadap Bacillus subtilis. Oleh karena itu daun jambu biji sering digunakan untuk mengobati penyakit diare, yang salah satunya disebabkan oleh Esherichia coli.

\section{Kesimpulan}

Berdasarkan hasil penelitian ekstraksi daun jambu biji tersebut membuktikan bahwa ekstrak daun jambu biji mempunyai aktivitas antioksidan terhadap Esherichia coli dan Bacillus subtilis. Sehingga daun jambu biji dapat dimanfaatkan untuk mengobati berbagai jenis penyakit.

\section{Daftar Pustaka}

Chludil, H.D., Corbino, G.B., and Leicarh, S.R.. 2008. Soil Quality Effects on Chenopodium album Flavonoid Content and Antioxidant Potential. Journal of Agricultural and Food Chemistry, Vol 56 (13), hal 5050-5056. 
Daud, M. F., Sadiyah, E.R, dan Rismawati, Endah. 2011. Pengaruh Perbedaan Metode Ekstraksi Terhadap Aktivitas Antioksidan Ekstrak Etanol Daun Jambu Biji (Psidium guajava L.) Bergading Buah Putih. Prosiding Seminar Nasional Penelitian dan PKM Sains, Teknologi dan Kesehatan. Vol 2 (1).

Indariani, Susi. 2010. Uji Aktivitas Antioksidan Ekstrak Daun Jambu Biji (Psidium guajava L.). Bogor: Departemen Kimia, FMIPA -IPB.

Kikuzaki H., M. Hisamoto, K. Hirose, K. Akiyama, H. Taniguchi. 2002. Antioxidants Properties of Ferulic Acid and Its Related Compound. J. Agric. Food Chem. 50. hal 2161 - 2168

Nurmuhaimina, S.A., Maulia, R. , Yuniarti, I., dan Umaningrum, D.. 2009. Uji Aktivitas Antioksidan Dari Ekstrak Campuran Tumbuhan Alang-Alang (Imperata cylindrica) dan Lidah Ular (Hedyotis corymbosa) Sebagai Peredam Radikal Bebas Asam Linoleat. Sains dan Terapan Kimia. Vol 2 (1).

Prakash, A., 2001, Antioxidant Activity. Medallion Laboratories. Vol 19 (2) : 59-63

Rohyami, Yuli. 2008. Penentuan Kandungan Flavonoid dari Ekstrak Metanol Daging Buah Mahkota Dewa (Phaleria macrocarpa Scheff Boerl). Jurnal Logika. Vol 5 (1).

Suradikusumah, E. 1989. Kimia Tumbuhan. Bogor: PAU-Institut Pertanian Bogor.

Tachakittirungrod, S., Ikegami, F., and Okonogi, S.. 2007. Antioxidant Active Principles Isolated from Psidium guajava Grown in Thailand. Scientia Pharmaceutica. Vol 75, hal 179-193.

Vijayakumar, A. Vijaya Anand, R. Manikandan. 2015. In Vitro Antioxidant Activity of Ethanolic Extract of Psidium guajava Leaves. Jurnal of Research Studies in Biosciences. Vol. 3 (2). hal 145 -149.
Zuhra, C.F., Tarigan, J.B., dan Sihotang, H.. 2008. Aktivitas Antioksidan Senyawa Flavonoid dari Daun Katuk (Sauropus androgunus (L) Merr.). Jurnal Biologi Sumatera. Vol 3 (1), hal 7-10 